\title{
Interactive comment on "Is Mass Transfer in Secondary Organic Aerosol Particles Intrinsically Slow? Equilibration Timescales of Engine Exhaust and $\alpha$-Pinene SOA Under Dry and Humid Conditions" by Khairallah Atwi et al.
}

\section{Anonymous Referee \#2}

Received and published: 18 April 2018

The authors present the evaporation kinetics of SOA formed from engine exhaust and $\alpha$-pinene SOA formed via photooxidation using their homemade oxidation flow reactor (OFR). The SOA produced by the OFR has mass loadings in excess of $100 \mu \mathrm{g} \mathrm{m}$ 3 , and $2.5 \mu \mathrm{g} \mathrm{m}-3$ and $5.0 \mu \mathrm{g} \mathrm{m}-3$ of the SOA is injected into their Teflon chamber for evaporation measurements. During the course of the evaporation measurements there is a small change in the peak diameter corresponding to $5-10 \%$ change in the volume of the particles after about an hour. When the size distribution is 'stable' the authors propose that there is no subsequent change in particle size because the SOA has 
reached equilibrium with the vapor phase. It is important to note, the peak diameter increases at long times due to the size-dependent wall loss exhibited during control experiments using ammonium sulfate aerosol. The evaporation kinetics are modeled with what can only be described as a simplistic single product model.

Beyond this I have major concerns about one of the main underlying assumptions that is used in the interpretation of the results. For the particles in the Teflon chamber they are assumed to evaporate or be lost to the walls and the authors treat these particles as able to evaporate or not based on an omega parameter, and this treatment is fine. However, the fate of the gas phase vapor that evaporates in the chamber is assumed to only stay in the gas phase and not partition or be lost to the walls. Recent studies have shown that gas vapors with a saturation vapor pressure between $0.01-100 \mu \mathrm{g}$ $\mathrm{m}-3$ will be lost to the walls, which act as a sink for all semivolatile vapors.[1-5] If it is assumed the saturation vapor concentration put forth in the paper is true, then it would be expected that the vapor would be lost to the walls during the course of the evaporation measurement and the system would never truly be at equilibrium. Without a measure of gas phase vapor concentrations or something continually scavenging the gas phase vapor (i.e. activated charcoal) simply letting the Teflon chamber act as a vapor sink makes it impossible to constrain the set of equations used by the authors. Because of this and the simplistic model used, mentioned at length in the other review, I do not recommend the publication of this paper.

Comments:

$\mathrm{Pg} 3 \ln 31$ : It seems odd cite those that did while not citing those that did not.

$\mathrm{Pg} 3$ In 33: There have been many studies that have investigated anthropogenic SOA... perhaps the authors mean that volatility measurements of anthropogenic SOA are what is limited.

$\mathrm{Pg} 4$ In 18: I find the discussion here needs to be significantly changed. Pg 4 In 18 references the evaporation coefficient $\alpha$, but it is not present in the set of equations that 
have been presented to that point.

$\mathrm{Pg} 4 \ln 25$ : What benefit and impact to the broader community is there to using such a simple model?

$\mathrm{Pg}$ 5: The significant limitation of this work is underlying assumption that the vapor phase only interacts with the particles in the chamber. As discussed above, not taking vapor wall losses into account makes this work untenable.

$\mathrm{Pg}$ 6: In this work the humidity of the evaporation chamber and the OFR are the same, to probe the effect of viscosity it would be more appropriate to try to study dry (formation) vs. wet (evaporation) and vice versa as performed in Wilson et al.[6] This comparison is important because the composition of SOA can be heavily dependent on the $\mathrm{RH}$ of formation, for an example see Hinks et al. for Toluene SOA.[7] As a result, the differences shown here between $\sim 10 \%$ and $60 \% \mathrm{RH}$ may not be the appropriate comparison.

$\mathrm{Pg} 7$ In 5-13: What are the dominant VOC emissions from this engine? It is difficult to conclusively say anything about the volatility of the SOA produced from this source without some knowledge of the precursors VOCs that are emitted. Also, are the primary emissions from the engine filtered out with the HEPA filter? If the primary organic aerosol is not filtered then what is the mass loading prior to the lights being turned on? Figure 4 suggests there is no OA mass concentration, but doesn't explicitly mention how this is measured or what experiment this is from.

$\mathrm{Pg}$ 7/8: Another point about the experimental setup is the difference in temperature between the OFR (24 C) and the evaporation chamber (32 C). Was there any reason for not operating both chambers at the same temperature?

$\mathrm{Pg} 9$ In 4: Does $\mathrm{k}$ change for every experiment? What range of $\mathrm{k}$ values are present for the experiments? In the abstract the saturation concentration is inconsistent with the results presented in the paper $(0.02-0.11$ vs. $0.2-1.2$ (see pg 10)). Also in the 
abstract there is a mention to the enthalpy of vaporization $(150 \mathrm{Kj} / \mathrm{mol})$ and I don't see this referred to in the rest of the paper. If this it isn't mentioned in the paper why is it in the abstract?

(1) Krechmer, J. E.; Pagonis, D.; Ziemann, P. J.; Jimenez, J. L. Environmental Science \& Technology 2016, 50, 5757, DOI:10.1021/acs.est.6b00606 (2) Krechmer, J. E.; Day, D. A.; Ziemann, P. J.; Jimenez, J. L. Environmental Science \& Technology 2017, 51, 11867, DOI:10.1021/acs.est.7b02144 (3) Huang, Y.; Zhao, R.; Charan, S. M.; Kenseth, C. M.; Zhang, X.; Seinfeld, J. H. Environmental Science \& Technology 2018, 52, 2134, DOI:10.1021/acs.est.7b05575 (4) La, Y. S.; Camredon, M.; Ziemann, P. J.; Valorso, R.; Matsunaga, A.; Lannuque, V.; Lee-Taylor, J.; Hodzic, A.; Madronich, S.; Aumont, B. Atmos. Chem. Phys. 2016, 16, 1417, DOl:10.5194/acp-16-1417-2016 (5) Trump, E. R.; Epstein, S. A.; Riipinen, I.; Donahue, N. M. Aerosol Science and Technology 2016, 50, 1180, DOI:10.1080/02786826.2016.1232858 (6) Wilson, J.; Imre, D.; Beránek, J.; Shrivastava, M.; Zelenyuk, A. Environmental Science \& Technology 2015, 49, 243, DOI:10.1021/es505331d (7) Hinks, M. L.; Montoya-Aguilera, J.; Ellison, L.; Lin, P.; Laskin, A.; Laskin, J.; Shiraiwa, M.; Dabdub, D.; Nizkorodov, S. A. Atmos. Chem. Phys. 2018, 18, 1643, DOI:10.5194/acp-18-1643-2018

Interactive comment on Atmos. Chem. Phys. Discuss., https://doi.org/10.5194/acp-2018-215, 2018. 